\title{
Takayasu arteritis: "bitten apple" in the aorta, odd finding in a plain X-ray
}

\author{
George E. Fragoulis ${ }^{1,2}\left(\mathbb{D} \cdot\right.$ Gerasimos Evangelatos $^{1} \cdot$ Alexios Iliopoulos $^{1}$
}

Received: 30 June 2019 /Revised: 18 July 2019 / Accepted: 24 July 2019/Published online: 2 August 2019

(C) International League of Associations for Rheumatology (ILAR) 2019

\section{Presentation}

A 57-year-old lady with a history of diabetes mellitus was admitted in our clinic with fatigue and raised ESR $(85 \mathrm{~mm} /$ 1st $\mathrm{h}$ ) and CRP (36 mg/L). Twelve years earlier, a stent had been placed for bilateral stenosis of aortoiliac arteries. One year after that, a CT (computed tomography) scan showed the atrophic left kidney and a CT angiography (CTA) revealed stenosis of both kidney arteries. An endovascular stent was placed in the right kidney artery (RKA). Patient did not seek for any further medical advice until her admission to our hospital.

A chest X-ray (CXR) performed in our clinic showed aortic arch and descending aorta stenosis, with post-stenotic dilatation (Fig. 1). Ultrasound (confirmed also by magnetic resonance angiography (MRA)) revealed $75 \%$ stenosis of the left common carotid and subclavian artery and total occlusion of the right common carotid and subclavian artery. Additionally, post-stent stenosis of $75 \%$ was observed in the RKA.

Patient was treated for Takayasu arteritis (TAK) with azathioprine $(2 \mathrm{mg} / \mathrm{kg}$ ) and methylprednisolone ( $30 \mathrm{mg} /$ day) with good response. During steroids tapering, disease relapsed and RKA stenosis advanced to $90 \%$. Infliximab $(5 \mathrm{mg} / \mathrm{kg}$ ) was commenced. Six months later, due to incomplete response, patient was switched to tocilizumab $(8 \mathrm{mg} / \mathrm{kg})$, that was continued for 6 years. Eventually, occlusion of the RKA led to

George E. Fragoulis and Gerasimos Evangelatos contributed equally to this work.

George E. Fragoulis

geofragoul@yahoo.gr

1417 "NIMTS", Rheumatology Department, Army Shared Fund Hospital, Monis Petraki 10-12 str, 11521 Athens, Greece

2 Institute of Infection, Immunity and Inflammation, University of Glasgow, Glasgow, UK initiation of kidney dialysis. She passed away 1 year later due to dialysis complications.

\section{Discussion}

TAK is a large-vessel vasculitis, encountered mainly in young females. It affects more frequently the aorta, its main branches, and the pulmonary arteries [1], demonstrating stenoses (more frequently) and dilatations. Its diagnosis is based on clinical and imaging findings. Ultrasound, CTA, positron emission tomography (PET) scan, and MRI are all considered valid imaging techniques for TAK diagnosis [2]. MRI is currently preferred, according to the recent EULAR guidelines [2]. For assessing disease activity, PET scan can be a very useful tool as it has been shown in a recent study, in which standard uptake value (SUV) scores exhibited very good sensitivity and specificity [3]. Plain CXR is almost always normal; however, non-specific findings such as scalloped pattern in the descending aorta and linear calcification of the aortic arch and descending aorta in early phases, and dilatation of the ascending aorta and rib notching in late phases have been described [4].

Differential diagnosis of this lesion includes some other autoimmune diseases. Stenosis of the aorta is not uncommon in giant cell arteritis with large vessel involvement and has also been described in patients with Cogan syndrome [5]. Additionally, some conditions associated with aortitis (aortic wall thickening) or chronic periaortitis (aortic wall thickening with surrounding fibrotic tissue), like IgG4-related disease or Bechet's disease, can relatively rarely produce stenoses in the aorta. However, these are usually not segmental $[5,6]$.

Biopsy of the arterial wall, which would be useful in the diagnostic approach, is not always achievable. Physical examination (e.g., oral ulcers in Bechet's disease) and acquisition of comprehensive medical history (e.g., age of onset), along with laboratory and imaging findings, will help the clinician in the differential diagnosis. Despite its rarity, this image reminds 


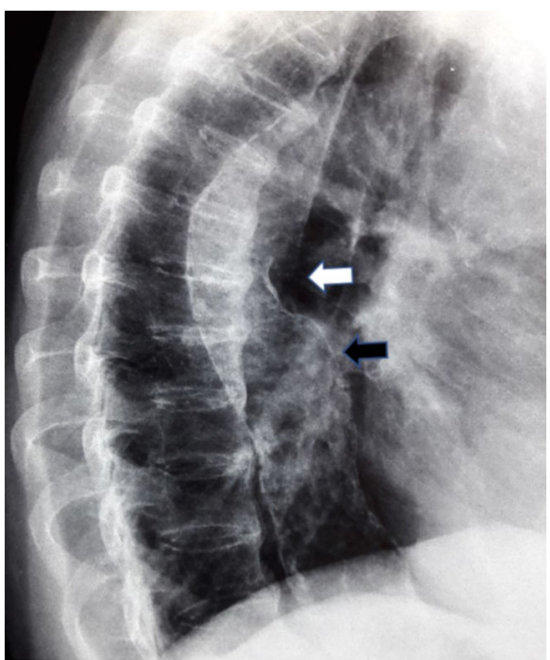

Fig. 1 Chest X-ray in a patient with Takayasu arteritis showing stenosis of aortic arch and descending aorta (resembling a "bitten apple," white arrow) with post-stenotic dilatation (black arrow)

that rheumatologists should keep in mind that a plain chest Xray could lead to diagnosis in patients with suspected vasculitis.

\section{Compliance with ethical standards}

\section{Disclosures None.}

Ethics and consent The patient has passed away. Thus, informed consent has been obtained from patient's relatives according to the Declaration of Helsinki. Ethical approval was not necessary as this is a report of an anonymized image.

\section{References}

1. Tombetti E, Mason JC (2018) Takayasu arteritis: advanced understanding is leading to new horizons. Rheumatology (Oxford) 58(2): 206-219. https://doi.org/10.1093/rheumatology/key040

2. Dejaco C, Ramiro S, Duftner C, Besson F, Bley T, Blockmans D et al (2018) EULAR recommendations for the use of imaging in large vessel vasculitis in clinical practice. Ann Rheum Dis 77:636-643. https://doi.org/10.1136/annrheumdis-2017-212649

3. Zhang X, Zhou J, Sun Y, Shi H, Ji Z, Jiang L (2018) 18F-FDG-PET/ CT: an accurate method to assess the activity of Takayasu's arteritis. Clin Rheumatol 37:1927-1935. https://doi.org/10.1007/s10067-0173960-7

4. Matsunaga N, Hayashi K, Sakamoto I, Ogawa Y, Matsumoto T (1997) Takayasu arteritis: protean radiologic manifestations and diagnosis. Radiographics 17:579-594

5. Stone JR, Bruneval P, Angelini A, Bartoloni G, Basso C, Batoroeva L, Buja LM, Butany J, d'Amati G, Fallon JT, Gittenberger-de Groot AC, Gouveia RH, Halushka MK, Kelly KL, Kholova I, Leone O, Litovsky SH, Maleszewski JJ, Miller DV, Mitchell RN, Preston SD, Pucci A, Radio SJ, Rodriguez ER, Sheppard MN, Suvarna SK, Tan CD, Thiene G, van der Wal AC, Veinot JP (2015) Consensus statement on surgical pathology of the aorta from the Society for Cardiovascular Pathology and the Association for European Cardiovascular Pathology: I. inflammatory diseases. Cardiovasc Pathol 24:267-278. https://doi.org/10.1016/j.carpath.2015.05.001

6. Palmisano A, Vaglio A (2009) Chronic periaortitis: a fibroinflammatory disorder. Best Pract Res Clin Rheumatol 23:339353. https://doi.org/10.1016/j.berh.2008.12.002

Publisher's note Springer Nature remains neutral with regard to jurisdictional claims in published maps and institutional affiliations. 